\title{
Penerapan Metode Composite Performance Index (CPI) Dalam Penerima Bantuan Kelompok Usaha Bersama (KUBE)
}

\author{
Zainab Sipahutar, Berto Nadeak, Putri Ramadhani \\ Program Studi Teknik Informatika, Universitas Budi Darma, Medan, Indonesia \\ Email: ${ }^{2}$ zainabsipahutar@gmail.com \\ Submitted: 03/12/2020; Accepted: 26/02/2021; Published: 30/05/2021
}

\begin{abstract}
Abstrak-Kelompok usaha bersama adalah sekelompok warga atau sekelompok masyarakat sosial yang dibentuk dari keluarga yang tergolong masyarakat miskin melalui program kesejahteraan sosial yang disingkat dengan prokesos yang berguna untuk melaksanakan usaha untuk menambah penghasilan sekelompok warga yang kurang mampu. Dalam proses pengambilan keputusan sering kali mengalami kesalahan dan kurang tepatnya penyaluran bantuan terhadap masyarakat, misalnya masyarakat yang sebenarnya tidak layak mendapat bantuan namun mendapatkan bantuan tersebut, berbanding terbalik dengan masyarakat yang miskin tidak mendapatkan bantuan. Masalah ini muncul karena kurang telitinya untuk memilih dan salah perhitungan dalam menentukan masyarakat yang berhak menerima bantuan untuk itu diperlukan Adanya suatu sistem pendukung keputusan dalam menghasilkan keputusan sehingga dapat mendukung keputusan yang dihasilkan oleh Dinsos provsu dengan lebih real. Pada penelitian ini digunakan salah satu metode Composite Performance Index (CPI) yang diharapkan mampu untuk membantu Dinsos provsu dalam menentukan kube yang layak dalam menerima bantuan
\end{abstract}

Kata Kunci: Sistem Pendukung Keputusan; Dinas Sosial; Provinsi; Kube; CPI

\begin{abstract}
A joint business group is a group of citizens or a group of social communities formed from families classified as poor communities through a social welfare program, abbreviated as prokesos, which is useful for carrying out business to increase the income of a group of underprivileged residents. In the decision-making process, errors and inaccuracies in the distribution of aid to the community, for example, people who do not deserve assistance but who receive assistance are inversely proportional to poor communities who do not receive assistance. This problem arises because of the lack of careful selection and miscalculation in determining which people are entitled to receive assistance. For this reason, it is necessary to have a decision support system in producing decisions so that it can support the decisions made by the Province of Social Affairs more real. In this study, one of the Composite Performance Index (CPI) methods is used which is expected to be able to assist the Provincial Social Service in determining the appropriate kube in receiving assistance.
\end{abstract}

Keywords: Decision Support System; Social Service; Province; Kube; CPI

\section{PENDAHULUAN}

Kelompok Usaha Bersama atau yang biasa disebut (KUBE) adalah sekelompok warga atau sekelompok masyarakat sosial yang dibentuk dari keluarga yang tergolong masyarakat miskin melalui program kesejahteraan sosial yang disingkat dengan prokesos yang berguna untuk melaksanakan usaha untuk menambah penghasilan sekelompok warga yang kurang mampu, saling berinteraksi sesama anggota kelompok dan mempengaruhi satu sama lain baik prilaku maupun keterampilan berusaha sesama kelompok. Kelompok usaha bersama (kube) ini adalah salah satu program bantuan pemerintah setiap provinsi melalui dinas sosial, salah satunya provinsi sumatera utara untuk mengurangi angka kemiskinan di indonesia.

Dalam mengadakan kegiatan bantuan kube ini adalah Dinas Sosial Provinsi Sumatera Utara yang ditangani bidang penanganan fakir miskin, terdapat dua penanganan yang dilakukan fakir miskin yaitu penanganan fakir miskin pedesaan dan fakir miskin perkotaan dan untuk pedesaan dinas sosial memberikan dana bantuan per kabupaten, pada bagian ini penulis meneliti penanganan dipedesaan menggunakan data penerima kube ditahun 2016 yang di proyeksikan pada kabupaten Labuhan batu utara, setiap calon penerima bantuan kube mendapatkan dana sebesar dua puluh juta per kelompok melalui rekening ketua kelompok kube yang sudah disepekati calon penerima bantuan kube dan kegiatan ini dibiayai oleh APBN, tetapi untuk mendapatkan dana tersebut tentu ada syarat dan kriteria yang harus dipenuhi setiap kelompok untuk menerima dana bantuan kube tersebut.

Permasalahan saat ini yang sering terjadi pada Dinas Sosial Provinsi Sumatera Utara dalam menangani bantuan kube ini adalah dalam menentukan kelompok yang layak menerima bantuan kube, karena dalam proses pengambilan keputusan sering kali mengalami kesalahan dan kurang tepatnya penyaluran bantuan terhadap kelompok masyarakat yang benar-benar layak untuk menerima bantuan tersebut. Terlebih lagi banyaknya proposal yang diajukan calon-calon penerima bantuan kube kepada dinas sosial provinsi sumatera utara. Masalah ini muncul karena kurang telitinya dalam menentukan penerima bantuan sehingga membutuhkan waktu yang cukup lama dalam menganalisa kelompok penerima, dan juga tanpa melakukan penilaian yang sistematis terhadap kelompok yang akan menerima bantuan tersebut, untuk itu penulis ingin membantu dinas sosial dalam menentukan kelompok yang layak menerima bantuan kube dengan aplikasi sistem pendukung keputusan dengan hasil yang lebih real.

Untuk itu diperlukan adanya suatu sistem yang membantu Dinas sosial pada bagian fakir miskin dalam mengambil keputusan yang tepat dalam menentukan penerima bantuan kube tersebut dengan sistematis, Sistem pendukung keputusan merupakan sistem yang digunakan untuk membantu user dalam mengambil keputusan dalam situasi yang semi terstruktur dan situasi yang tidak terstruktur dan biasanya dibangun untuk mendukung solusi atau suatu masalah yang dihadapi oleh user dengan alternatif kriteria yang terbaik [1]. Dalam proses 
pengambilan keputusan penerima bantuan kelompok usaha bersama (kube), sistem pendukung keputusan ini sangat dibutuhkan agar dapat membantu user dalam mengambil keputusan yang tepat untuk menentukan penerima bantuan kube tersebut dengan lebih efesien dan tersistematis.

Dan juga diperlukannya suatu metode untuk menyelesaikan sistem pendukung keputusan tersebut, supaya hasil yang diharapkan lebih akurat dan sistem yang dirancang tersusun secara sistematis, maka dalam hal ini penulis mengambil metode Composite Performance Index (CPI ). Pada penelitian sebelumnya yang dilakukan mahasiswa Stmik Budidarma metode ini sangat cocok digunakan dalam pembuatan suatu sistem pendukung keputusan penerima bantuan karena dapat digunakan untuk memilih beberapa alternatif. Model pendukung keputusan dengan metode Composite Performance Index ini dengan index gabungan dapat digunakan untuk memilih berbagai alternatif yang berdasarkan beberapa kriteria, semakin tinggi nilainya maka akan semakin baik [2].

\section{METODE PENELITIAN}

\subsection{Sistem Pendukung Keputusan}

DSS (Decision Support System) merupakan sistem informasi interaktif yang menyediakan informasi, pemodelan, dan pemanipulasian data. Sistem itu digunakan untuk membantu pengambilan keputusan dalam situasi yang semi terstruktur dan situasi yang tidak terstruktur. DSS (Decision Support System) biasanya dibangun untuk mendukung solusi atas suatu masalah atau mengevaluasi suatu peluang[3]-[5].

\subsection{Bantuan}

Bantuan adalah bantuan berupa uang/barang dari pemerintah kepada individu, keluarga, kelompok dan/atau masyarakat yang sifatnya tidak secara terus menerus dan selektif yang bertujuan untuk memberikan rangsangan, dorongan untuk melindungi dari kemungkinan terjadinya resiko sosial[6].

\subsection{Metode Composite Performance Index (CPI)}

Composite performance index yang merupakan indeks gabungan (composite performance index) dapat digunakan untuk menentukan penilaian atau peringkat dari berbagi alternatif (i) berdasarkan beberapa kriteria (j) [7]. Metode Composite performance index merupakan salah satu metode perhitungan dari pengambilan keputusan berbasis index kinerja, metode composite performance index digunakan untuk penilaian dengan kriteria yang tidak seragam. Index gabungan (composite performance index) dapat digunakan untuk menentukan penentuan atau peringkat dari berbagai alternatif berdasarkan beberapa kriteria[2], [8].

Formula yang digunakan dalam teknik dari metode composite performance index adalah sebagai berikut[7]:

$$
\begin{array}{ll}
\mathrm{A}_{\mathrm{ij}} & =\left(\mathrm{X}_{\mathrm{ij}}(\min ) / \mathrm{X}_{\mathrm{ij}}(\min )\right) \times 100 \\
\mathrm{~A}_{(\mathrm{I}+1, \mathrm{j})} & =\left(\mathrm{X}_{(\mathrm{I}+1 . \mathrm{j})} / \mathrm{X}_{\mathrm{ij}}(\min )\right) \times 100 \\
\mathrm{I}_{\mathrm{ij}} & =\mathrm{A}_{\mathrm{ij}} \mathrm{X} \mathrm{P}_{\mathrm{j}} \\
\mathrm{I}_{\mathrm{i}} & =\sum_{j=1}^{n} I i j
\end{array}
$$

Keterangan:

$$
\begin{array}{ll}
\mathrm{A}_{\mathrm{ij}} & =\text { nilai alternatif ke- } \mathrm{i} \text { pada kriteria ke- } \mathrm{j} \\
\left(\mathrm{X}_{\mathrm{ij}}(\mathrm{min})\right. & =\text { nilai alternatif ke- } \mathrm{i} \text { pada kriteria awal minimum ke- } \mathrm{j} \\
\left(\mathrm{X}_{(\mathrm{I}+1 . \mathrm{j})}=\text { nilai alternatif ke- } \mathrm{i}+1\right. \text { [ada kriteria awal ke-j] } & =\text { bobot kepentingan kriteria ke- } \mathrm{j} \\
\mathrm{P}_{\mathrm{j}} & =\text { indeks alternatif ke-i } \\
\mathrm{I}_{\mathrm{ij}} & =\text { indeks gabungan kriteria pada alternatif ke-i } \\
\mathrm{I}_{\mathrm{i}} & =1,2,3, \ldots, \mathrm{n} \\
\mathrm{i} & =1,2,3, \ldots, \mathrm{m}
\end{array}
$$

Prosedur penyelesaian composite performance index disebutkan sebagai berikut:

1. Identifikasi kriteria tren yaitu positif (semangkin tinggi nilainya semangkin baik)

2. Untuk kriteria tren positif, nilai minimum pada setiap kriteria ditransformasi ke seratus, sedangkan nilai lainya ditransformasikan lebih rendah

3. Perhitungan nilai alternatif merupakan jumlah dari perkalian antara nilai kriteria dengan bobot kriteria.

4. Perhitungan alternatif menjadi rangking ditentukan berdasarkan perhitungan bayes.

\section{HASIL DAN PEMBAHASAN}

Analisa merupakan tahapan awal yang dilakukan untuk memecahkan sebuah permasalahan yang sedang terjadi. Tahap analisa ini sangat penting karena proses analisis yang akurat akan menghasilkan sebuah perangkat lunak yang dapat digunakan untuk pengguna. Dalam proses pengambilan keputusan sering kali mengalami kesalahan dan kurang tepatnya penyaluran bantuan terhadap masyarakat, misalnya kelompok masyarakat yang sebenarnya tidak layak mendapat bantuan namun mendapatkan bantuan tersebut, berbanding terbalik dengan kelompok 
masyarakat yang miskin tidak mendapatkan bantuan. Masalah ini muncul karena dalam suatu instansi pemerintah sering kali mengalami kesulitan dalam mendapatkan keputusan, karena dalam perhitungan yang dilakukan sering kali mengalami kesalahan dan waktu yang dibutuhkan cukup lama untuk menentukan kelompok masyarakat yang berhak menerima bantuan. Sehingga keputusan yang diambil sering kali mengalami kesalahan.

Sistem yang berjalan saat ini, pada kantor Dinas Sosial provinsi Sumatera Utara yang dirasa kurang mendapat hasil yang kurang optimal dalam mengambil keputusan. Maka dari itu penulis bermaksud untuk membuat suatu Sistem pendukung keputusan untuk membantu Dinas Sosial Sumatera Utara dalam proses pemilihan penerima bantuan kube dengan tepat dengan hasil yang lebih real.

\subsection{Penerapan Metode CPI}

Pada metode CPI ada beberapa tahapan proses yang harus diselesaikan dari bebrapa data alternatif dan juga kriteria yang ditentukan terlebih dahulu

Tabel 1. Alternatif Kelompok Usaha Bersama Dengan Masing-Masing Kriteria

\begin{tabular}{llllll}
\hline & C1 & C2 & C3 & C4 & C4 \\
\hline A1 & 65 & 50 & 65 & 100 & 35 \\
A2 & 65 & 100 & 65 & 100 & 65 \\
A3 & 100 & 50 & 35 & 100 & 100 \\
A4 & 65 & 50 & 100 & 65 & 65 \\
A5 & 35 & 50 & 35 & 100 & 35 \\
\hline
\end{tabular}

Dari tabel diatas, maka data akan diubah kedalam nilai matriks keputusan $\mathrm{X}$ dengan data

1. Perhitungan Nilai Usia

$$
x=\left[\begin{array}{ccccc}
0.20 & 0.10 & 0.20 & 0.35 & 0.10 \\
0.20 & 0.35 & 0.20 & 0.35 & 0.20 \\
0.35 & 0.10 & 0.10 & 0.35 & 0.35 \\
0.20 & 0.10 & 0.35 & 0.20 & 0.20 \\
0.10 & 0.10 & 0.10 & 0.35 & 0.10
\end{array}\right]
$$

Tren pada kriteria nilai rata-rata usia setiap kelompok penerima bantuan adalah (-), dimana semakin rendah nilainya, akan semakin baik.

Tren $(-)=$ Nilai min/Nilai $\mathrm{N} * 100$

$35 / 65=0.53846154 * 100=53.846154$

$35 / 65=0.53846154 * 100=53.846154$

$35 / 100=0.35 \quad * 100=35$

$35 / 65=0.53846154 * 100=53.846154$

$35 / 35=1 \quad * 100=100$

Tabel 2. Tabel Kriteria Usia

\begin{tabular}{lllll}
\hline Kriteria & Alternatif & \multicolumn{1}{c}{ Usia } & \multicolumn{1}{c}{ N/Min } & N/Min * 100 \\
\hline C1 & $\mathrm{A}_{1}$ & 65 & 0.53846154 & 53.846154 \\
$\mathrm{C} 2$ & $\mathrm{~A}_{2}$ & 65 & 0.53846154 & 53.846154 \\
$\mathrm{C} 3$ & $\mathrm{~A}_{3}$ & 100 & 0.35 & 35 \\
$\mathrm{C} 4$ & $\mathrm{~A}_{4}$ & 65 & 0.53846154 & 53.846154 \\
$\mathrm{C} 5$ & $\mathrm{~A}_{5}$ & 35 & 1 & 100 \\
\hline
\end{tabular}

2. Perhitungan kelengkapan dokumen kelompok

Tren pada kriteria nilai kelengkapan dokumen kelompok yang akan menerima bantuan adalah (-), dimana semakin rendah nilainya, akan semakin baik.

Tren $(-)=$ Nilai min $/$ Nilai $\mathrm{N} * 100$

$50 / 50=1 * 100=100$

$50 / 100=0.5 * 100=50$

$50 / 50=1 * 100=100$

$50 / 50=1 * 100=100$

$50 / 50=1 * 100=100$

Tabel 3. Tabel Kriteria Dokumen

\begin{tabular}{lllll}
\hline Kriteria & Alternatif & Dokumen & N/Min & N/Min * 100 \\
\hline $\mathrm{C} 1$ & $\mathrm{~A}_{1}$ & 50 & 1 & 100 \\
$\mathrm{C} 2$ & $\mathrm{~A}_{2}$ & 100 & 0.5 & 50 \\
$\mathrm{C} 3$ & $\mathrm{~A}_{3}$ & 50 & 1 & 100 \\
$\mathrm{C} 4$ & $\mathrm{~A}_{4}$ & 50 & 1 & 100 \\
$\mathrm{C} 5$ & $\mathrm{~A}_{5}$ & 50 & 1 & 100 \\
\hline
\end{tabular}


3. Perhitungan nilai kerja sama

Tren pada kriteria untuk nilai kerja sama antar kelompok yang akan menerima bantuan adalah (+), dimana semakin tinggi nilainya, akan semakin baik.

Tren $(+)=$ Nilai N / Nilai min $* 100$

$65 / 35=1.85714286 * 100=185.714286$

$65 / 35=1.85714286 * 100=185.714286$

$35 / 35=1 \quad * 100=100$

$100 / 35=2.85714286 * 100=285.714286$

$35 / 35=1 \quad * 100=100$

Tabel 4. Tabel Kriteria Kerja Sama

\begin{tabular}{lllll}
\hline Kriteria & Alternatif & Kerja Sama & \multicolumn{1}{c}{ N/Min } & N/Min * 100 \\
\hline C1 & $\mathrm{A}_{1}$ & 65 & 1.85714286 & 185.714286 \\
$\mathrm{C} 2$ & $\mathrm{~A}_{2}$ & 65 & 1.85714286 & 185.714286 \\
$\mathrm{C} 3$ & $\mathrm{~A}_{3}$ & 35 & 1 & 100 \\
$\mathrm{C} 4$ & $\mathrm{~A}_{4}$ & 100 & 2.85714286 & 285.714286 \\
$\mathrm{C} 5$ & $\mathrm{~A}_{5}$ & 35 & 1 & 100 \\
\hline
\end{tabular}

4. Perhitungan nilai keterampilan berusaha

Tren pada kriteria untuk nilai keterampilan berusaha kelompok yang akan menerima bantuan adalah (+), dimana semakin tinggi nilainya, akan semakin baik.

Tren $(+)=$ Nilai N / Nilai $\min * 100$
$100 / 65=1.53846154$
$* 100=153.846154$
$100 / 65=1.53846154$
$* 100=153.846154$
$100 / 65=1.53846154$
$* 100=153.846154$
$65 / 65=1$
$* 100=100$
$100 / 65=1.53846154$
$* 100=153.846154$

Tabel 5. Tabel Kriteria keterampilan

\begin{tabular}{lllll}
\hline Kriteria & Alternatif & Keterampilan & N/Min & N/Min *100 \\
\hline $\mathrm{C} 1$ & $\mathrm{~A}_{1}$ & 100 & 1.5 & 153.8 \\
$\mathrm{C} 2$ & $\mathrm{~A}_{2}$ & 100 & 1.5 & 153.8 \\
$\mathrm{C} 3$ & $\mathrm{~A}_{3}$ & 100 & 1.5 & 153.8 \\
$\mathrm{C} 4$ & $\mathrm{~A}_{4}$ & 65 & 1 & 100 \\
$\mathrm{C} 5$ & $\mathrm{~A}_{5}$ & 100 & 1.5 & 153.8 \\
\hline
\end{tabular}

5. Perhitungan nilai pendapatan kube

Tren pada kriteria untuk nilai pendapatn kube kelompok yang akan menerima bantuan adalah $(+)$, dimana semakin tinggi nilainya, akan semakin baik.

$$
\begin{aligned}
& \text { Tren }(+)=\text { Nilai N / Nilai min } * 100 \\
& 35 / 35=1 \quad * 100=100 \\
& 65 / 35=1.85714286 * 100=185.714286 \\
& 100 / 35=2.85714286 * 100=285.714286 \\
& 65 / 35=1.85714286 * 100=185.714286 \\
& 35 / 35=1 \quad * 100=100
\end{aligned}
$$

Tabel 6. Tabel Kriteria Pendapatan

\begin{tabular}{ccccc}
\hline Kriteria & Alternatif & Keterampilan & N/Min & N/Min * 100 \\
\hline C1 & $\mathrm{A}_{1}$ & 35 & 1 & 100 \\
$\mathrm{C} 2$ & $\mathrm{~A}_{2}$ & 65 & 1.85714286 & 185.714286 \\
$\mathrm{C} 3$ & $\mathrm{~A}_{3}$ & 100 & 2.85714286 & 285.714286 \\
$\mathrm{C} 4$ & $\mathrm{~A}_{4}$ & 65 & 1.85714286 & 185.714286 \\
$\mathrm{C} 5$ & $\mathrm{~A}_{5}$ & 35 & 1 & 100 \\
\hline
\end{tabular}

Perhitungan CPI

$\mathrm{CPI}=$ nilai_kriteria $1 *$ bobot + nilai_kriteria $2 *$ bobot + nilai_kriteria $3 *$ bobot + nilai_kriteria $4 *$ bobot + nilai_kriteria $5 *$ bobot

Perhitungan $\mathrm{A}_{1}$

$$
\begin{aligned}
\mathrm{CPI} & =53.846154 * 0.10+100 * 0.15+185.714286 * 0.35+153.846154 * 0.20+100 * 0.20 \\
& =5.3846154+15+65.0000001+30.7692308+20 \\
& =136.153846
\end{aligned}
$$

Perhitungan $\mathrm{A}_{2}$ 


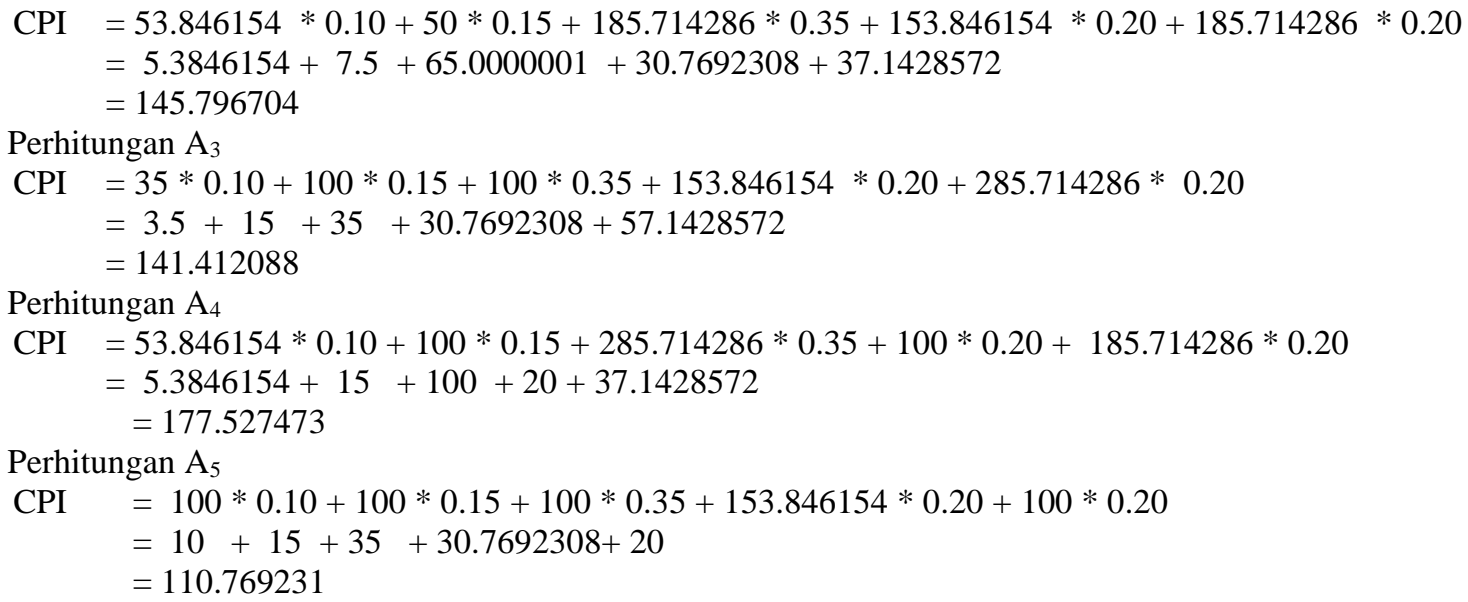

Berikut ini adalah tabel hasil perhitungan CPI berdasarkan peringkat sebagai berikut :

Tabel 7. hasil peringkat CPI

\begin{tabular}{ccc}
\hline Alternatif & Nilai CPI & Peringkat \\
\hline $\mathrm{A}_{4}$ & 177.527473 & 1 \\
$\mathrm{~A}_{2}$ & 145.796704 & 2 \\
$\mathrm{~A}_{3}$ & 141.412088 & 3 \\
$\mathrm{~A}_{1}$ & 136.153846 & 4 \\
$\mathrm{~A}_{5}$ & 110.769231 & 5 \\
\hline
\end{tabular}

Penerapan CPI dari 5 alternatif penerima kube diatas menghasilkan $A_{4}>A_{3}>A_{1}>A_{2}>A_{5}$, sehingga diputuskan bahwa kelompok kube $\mathrm{A}_{4}$ dan $\mathrm{A}_{2}$ merupakan alternatif yang dipilih untuk mendapatkan dana bantuan

\subsection{Implementasi Program}

Menu Input Penerima Bantuan Kube merupakan menu yang berisi tentang data dan nilai penerima bantuan Kube. Tampilan Menu Input Penerima bantuan Kube dapat dilihat pada gambar 1 di bawah ini :

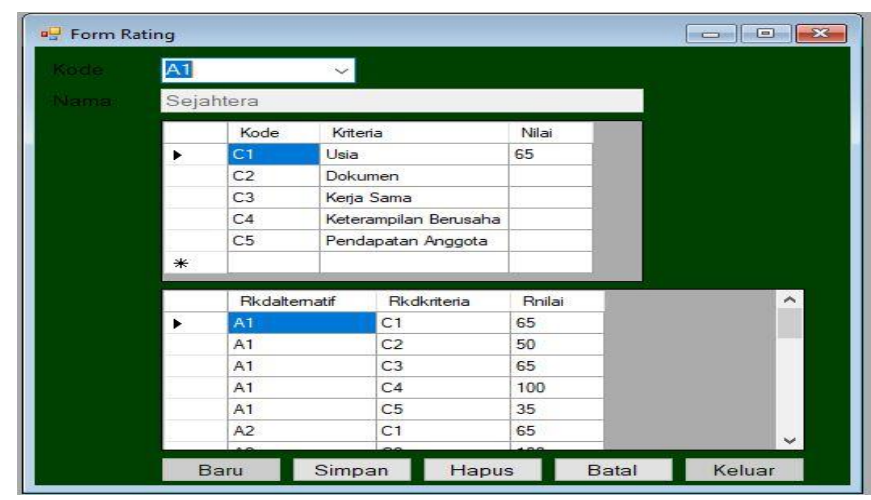

Gambar 1. Form input Penerima Bantuan Kube

Setelah Melakukan proses penerima bantuan Kube dengan menerapkan metode CPI mendapatkan hasil seperti gambar 2 dibawah ini:

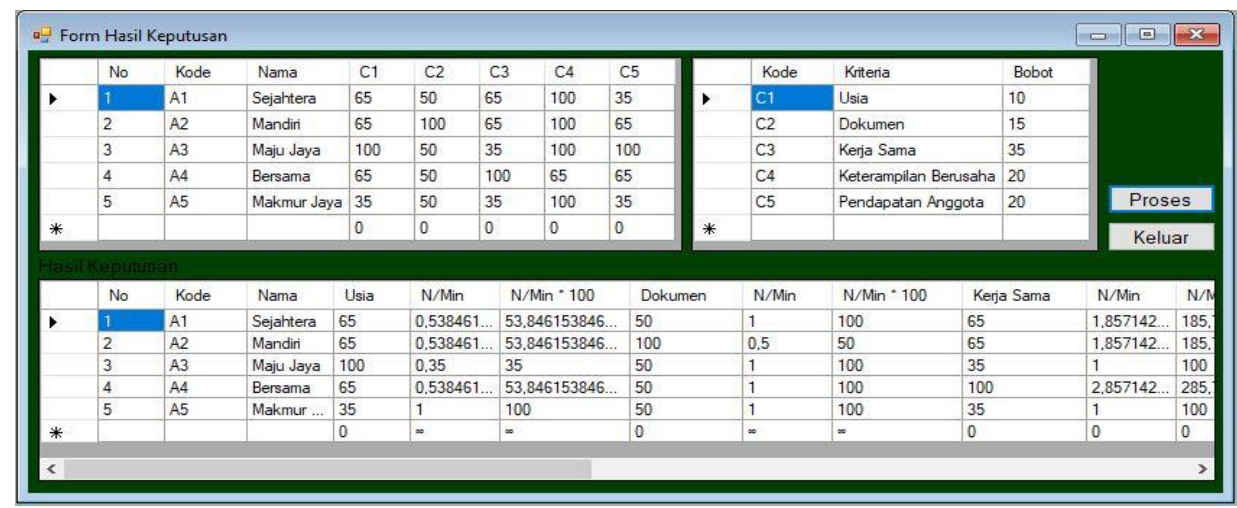

Gambar 2. Form Hasil Proses Penerima Bantua Kube 


\section{KESIMPULAN}

Berdasarkan hasil dari penelitian yang telah penulis lakukan, maka dapat diambil kesimpulan Sistem ini dapat membantu proses penerima bantuan kelompok usaha bersama berdasarkan penjumlahan terbobot dan kriteriakriteria yang telah ditentukan. Metode Composite Performance Index (CPI) ini dapat diterapkan dalam penentuan penerima bantuan kelompok usaha bersama (Kube) karena dapat digunakan untuk memilih beberapa alternatif dari beberapa kriteria. Sistem ini dapat dirancang untuk menentukan penerima bantuan kelompok usaha bersama (Kube) dengan menggunakan Visual Basic.Net 2008 dan Database MYSQL.

\section{REFERENCES}

[1] M. ko. Kusrini, "Konsep Dan Aplikasi Sistem Pendukung Keputusan,” Fl. Sigit Suyantoro, Ed. Yogyakarta,.

[2] N. S. Tanjung, P. D. Adelina, M. K. Siahaan, E. Purba, and J. Afriany, "Sistem Pendukung Keputusan Pemilihan Guru Teladan Dengan Menggunakan Metode Composite Performance Index (CPI),” J. Ris. Komput. (JURIKOM, vol. 5, no. 1, pp. 13-18, 2018.

[3] Kusumadewi, Multi-Attribute Decision. 2006.

[4] T. Limbong et al., Sistem Pendukung Keputusan: Metode \& Implementasi. Medan: Yayasan Kita Menulis, 2020.

[5] D. Nofriansyah, Multi Criteria Decision Making. Yogyakarta: Deepublish, 2017.

[6] "1 Panduan Identifikasi Penerima Bantuan UEP \& RS-RTLH PFM Pesisir, PPK \& PAN."

[7] R. Santoso, U. Nusantara, P. Guru, and R. Indonesia, "Beasiswa Menggunakan Metode Comparative Performance Index ( Cpi )," pp. 1-10, 2016.

[8] R. Rahim, Mesran, A. P. U. Siahaan, and S. Aryza, "Composite Performance Index for Student Admission," Int. J. Res. Sci. Eng., vol. 3, no. 3, 2017. 